\title{
Desafios para a transversalização curricular da Educação Ambiental no Ensino Religioso
}

\author{
Claudia Lourenço Gomes \\ Marília Andrade Torales Campos \\ Universidade Federal do Paraná (Brasil)
}

\section{Resumo}

Este artigo resulta de uma pesquisa realizada no contexto da rede municipal de ensino do município de Curitiba (PR-Brasil). Objetivou-se descrever os desafios apontados por um grupo de professoras para a inserção da Educação Ambiental no componente curricular de Ensino Religioso por meio da transversalização curricular. $\bigcirc$ estudo está ancorado em uma abordagem qualitativa com uso de entrevistas semiestruturadas. Dialogamos com Trevisol (2003), Sauvé (2005), Viana e Oliveira (2006), Meira (2009) e Torales-Campos (2015), para compor os fundamentos do campo da Educação Ambiental, e com Freitas (2018) para aprofundar os conhecimentos relacionados ao Ensino Religioso. A partir dos relatos das participantes, constatou-se que existem diferentes fatores, por vezes isolados ou integrados, que limitam a ação dos professores. Esses fatores compõem, com diferentes graus de impacto, um complexo conjunto de desafios a serem superados para que as práticas de Educação Ambiental sejam potencializadas no Ensino Religioso.

Palavras-chave: Desafios. Transversalidade. Educação ambiental. Ensino religioso.

\section{Challenges for curricular transversalization of Environmental Education in Religious Education}

\begin{abstract}
This article is the result of a research carried out in the context of municipal education network of Curitiba municipality (PR-Brazil). The objective was to describe the challenges pointed out by a group of teachers for the insertion of Environmental Education in the curricular component of Religious Education through curricular transversalization. The study is anchored in a qualitative approach, using semi-structured interviews. We dialogued with Trevisol (2003), Sauvé (2005), Viana and Oliveira (2006), Meira (2009) and Torales-Campos (2015), to compose the foundations of the field of Environmental Education, and with Freitas (2018) to deepen the knowledge related to Religious Education. From the reports of the participants, it was found that there are different factors, sometimes isolated or integrated, that limit the actions of teachers. These factors compose, with different degrees of impact, a complex set of challenges to be overcome so that Environmental Education practices are enhanced in Religious Education.

Keywords: Challenges. Transversality. Environmental education. Religious education.
\end{abstract}




\section{Desafíos para la transversalización del currículo de Educación Ambiental en Educación Religiosa}

\section{Resumen}

Este artículo es el resultado de una investigación realizada en el contexto de la red municipal de educación de la ciudad de Curitiba (PR-Brasil). El objetivo fue describir los desafíos señalados por un grupo de docentes para la inserción de la Educación Ambiental en el componente curricular de Enseñanza Religiosa a través del currículo transversal. El estudio está anclado en un enfoque cualitativo, utilizando entrevistas semiestructuradas. Dialogamos con Trevisol (2003), Sauvé (2005), Viana y Oliveira (2006), Meira (2009) y Torales-Campos (2015), para componer los fundamentos del campo de la Educación Ambiental, y con Freitas (2018) para profundizar el conocimiento relacionado con la Enseñanza Religiosa. A partir de los informes de los participantes, se desprende que existen diferentes factores a veces aislados o integrados, que limitan la acción de los docentes. Estos factores componen, con diferentes grados de impacto, un conjunto complejo de desafíos a superar para que las prácticas de Educación Ambiental se potencien en la Enseñanza Religiosa.

Palabras clave: Desafíos. Transversalidad. Educación ambiental. Enseñanza religiosa.

\section{Introdução}

Este artigo surge a partir dos resultados de uma pesquisa desenvolvida com a participação de professores que atuam no componente curricular de Ensino Religioso na rede pública municipal de Curitiba (PR-Brasil). Do ponto de vista teórico, a pesquisa tratou de abordar os processos de transversalização curricular a partir da interpretação dos professores sobre os conteúdos específicos dessa área do conhecimento, com base nos documentos norteadores desta prática educativa (BRASIL, 1997, 1999, 2012, 2017, 2019) em diálogo com as pesquisas sobre o tema.

Os dados foram produzidos a partir da realização de entrevistas semiestruturadas com um grupo de seis professoras que atuam nos anos iniciais do ensino fundamental da rede de ensino público municipal de Curitiba (PR-Brasil). Essas professoras foram selecionadas por seu tempo de atuação na disciplina e pela relevância de suas experiências e práticas profissionais. Para identificá-las, recorreu-se às informações oferecidas pela gerência do currículo (equipe de apoio pedagógico) do Ensino Religioso da Secretaria Municipal de Educação de Curitiba. 
Do grupo indicado, seis professoras aceitaram participar voluntariamente do estudo. Cabe destacar que, como todas as participantes eram mulheres, ao nos referirmos a elas, trataremos sempre em concordância com o gênero feminino. E, posteriormente, nos referiremos a elas como P1, P2, P3, P4, P5 e P6 para efeitos de análise.

Neste artigo, apresentam-se os dados analisados e discutidos com base na seguinte questão norteadora: "quais seriam os maiores desafios para a transversalização curricular da Educação Ambiental no componente de Ensino Religioso?". Essa questão surge pelo interesse em elucidar como a transversalidade é compreendida pelas professoras e quais relações elas estabelecem entre os temas contemporâneos sugeridos na Base Nacional Comum Curricular - BNCC (BRASIL, 2017). Ainda investigamos a organização didático-pedagógica de suas práticas para o ensino dos conteúdos previstos no Ensino Religioso.

Mais especificamente, é importante destacar que a temática ambiental se constitui em um dos maiores desafios a serem enfrentados pelas sociedades contemporâneas. Por isso, conforme disposto em diferentes documentos orientadores dos sistemas de ensino, alguns autores (STEVENSON, 2007; AGUILAR; KRASNY, 2011 ) destacam a importância de tratar esse tema no contexto escolar, pois é importante que a escola viabilize a reflexão sobre tais temas, de tal sorte a firmar seus compromissos com a transformação social a partir de uma ação política, engajada na luta pelos direitos democráticos de enfrentamento dos problemas que surgem no âmbito social e comunitário, tendo em vista que a escola não está incólume a eles.

Outrossim, compreende-se que a ação curricular da escola está em constante processo de transformação, já que é pródiga de novas demandas e desafios, constituindo-se como fértil espaço de diálogo, permeado por diferentes saberes que atravessam e transbordam os conteúdos curriculares, objetivando a construção de conhecimentos e a busca por respostas para solucionar os problemas através do agir por meio de múltiplos olhares a partir dessa integração transversal e interdisciplinar (PRESTINI, 2005; PEREIRA SOBRINHO; ZANON, 2016). 
Desafios para a transversalização curricular da Educação Ambiental no Ensino Religioso

\section{Transversalidade da Educação Ambiental}

A Educação Ambiental é reconhecida como um campo teórico diverso, plural e que permite a coexistência de diferentes abordagens. Portanto, está consolidada a partir de diferentes conceitos e correntes (SAUVÉ, 2005), mas comprometida com a luta por mudanças que levem à superação da crise socioambiental (TREVISOL, 2003) e civilizatória (MEIRA, 2009) em que as sociedades estão imersas.

No contexto educacional brasileiro, a Educação Ambiental se insere nos currículos escolares a partir da promulgação dos Parâmetros Curriculares Nacionais (PCNs), no ano de 1997. No documento, sua ação constitui-se pela proposta didática da transversalidade. Essa orientação denota o entendimento de que a melhor maneira de realizar a Educação Ambiental é pelo "atravessamento" de seus temas nos conteúdos de todas as áreas do conhecimento e componentes curriculares, de forma a estar presente em todos, conforme aponta a Lei n 9.795, de abril de 1999, que propõe a Política Nacional de Educação Ambiental (PNEA). Tal orientação também está presente nas Diretrizes Curriculares para a Educação Ambiental (DCNEA), publicada na Resolução n 42 2, de julho de 2012.

Em 2017, com a publicação da BNCC (BRASIL, 2017), repete-se essa mesma orientação, isto é, reforça-se o entendimento de que a Educação Ambiental deve ser tratada por meio dos temas contemporâneos transversais (TCTs). $\bigcirc$ mesmo documento também salienta que a prática educativa tem a incumbência de incorporar nos currículos e nas propostas pedagógicas a aproximação dos temas que afetam a vida humana em todas as escalas de forma transversal e integradora (BRASIL, 2017).

A partir da BNCC, a Educação Ambiental se reafirma como ocupante de um espaço no currículo escolar de cada componente, assegurando que o fazer pedagógico deve superar a fragmentação das disciplinas e relacionar os conteúdos escolares à realidade vivida (BRASIL, 2019).

Se, por um lado, as escolas possuem orientações para a inserção da Educação Ambiental, por outro, estudos (VIANA; OLIVEIRA, 2006; NEVES; TOZONI-REIS, 2014; TORALES-CAMPOS, 2015) indicam que tratar da transversalidade da Educação Ambiental é um desafio. 
Nessa perspectiva, os estudos supramencionados afirmam que a Educação Ambiental está presente nas escolas por intermédio de projetos e ações pontuais, predominantemente desenvolvidos pelas áreas de Ciências Naturais. Os mesmos autores destacam a complexidade de elementos que estão envolvidos nas práticas pedagógicas relacionadas à Educação Ambiental e apontam as dificuldades para abordar as temáticas ambientais de maneira transversal no currículo escolar. Dessa forma, esses estudos sublinham que é necessário assumir uma postura e uma decisão pedagógica crítica e politicamente engajada em relação à inserção e à potencialização da Educação Ambiental na escola.

Diante dessas afirmações, buscamos identificar quais são os possíveis impasses que dificultam a inserção da Educação Ambiental nas práticas educativas cotidianas das escolas e no Ensino Religioso, reconhecido como componente curricular obrigatório e essencial para a formação básica do cidadão. Nossa intenção é apontar caminhos para tornar possível a elaboração de intervenções pedagógicas que possam contribuir para a formação de sujeitos mais cientes das complexidades humanas, sociais e planetárias (MORIN, 2015).

\section{Ensino Religioso}

No Brasil, o Ensino Religioso está presente na Educação escolar desde a criação do sistema de ensino. Trata-se de um componente curricular que possui orientações específicas na Lei de Diretrizes e Bases da Educação Nacional (LDBN/1996). Na seção V, o art. 33, aponta que a disciplina deve ser assim organizada:

Oensino religioso, de matrícula facultativa, é parte integrante da formação básica do cidadão e constitui disciplina dos horários normais das escolas públicas de ensino fundamental, assegurado o respeito à diversidade cultural religiosa do Brasil, vedadas quaisquer formas de proselitismo.

$\S 1^{\circ}$ Os sistemas de ensino regulamentarão os procedimentos para a definição dos conteúdos do ensino religioso e estabelecerão as normas para a habilitação e admissão dos professores. 
Desafios para a transversalização curricular da Educação Ambiental no Ensino Religioso

$\S 2^{\circ}$ Os sistemas de ensino ouvirão entidade civil, constituída pelas diferentes denominações religiosas, para a definição dos conteúdos do ensino religioso (BRASIL, 1996, p. 13).

Dessa forma, vale sopesar que o Ensino Religioso é entendido como componente curricular necessário para a formação das pessoas e exercício da cidadania e a sua oferta obrigatória é estabelecido pela Lei no ensino fundamental, mesmo que de matrícula facultativa. No entanto, não se pode deixar de sublinhar que, em respeito ao princípio constitucional de laicidade do Estado e do reconhecimento da diversidade cultural religiosa, o documento veda a possiblidade de qualquer tipo de ação que se caracterize no âmbito do proselitismo e assegura seu desenvolvimento nos horários normais das escolas públicas.

Na Base Nacional Comum Curricular-BNCC (BRASIL, 2017), o documento mais atual que orienta a prática educativa e os currículos dos sistemas de ensino na escola, em relação ao Ensino Religioso, pela "[...] primeira vez se estabelecem direitos de aprendizagem para esta área de conhecimento" (FREITAS, 2018, p. 154).

Ensino Religioso busca construir, por meio do estudo dos conhecimentos religiosos e das filosofias de vida, atitudes de reconhecimento e respeito às alteridades. Trata-se de um espaço de aprendizagens, experiências pedagógicas, intercâmbios e diálogos permanentes, que visam o acolhimento das identidades culturais, religiosas ou não, na perspectiva da Interculturalidade, direitos humanos e cultura da paz. Tais finalidades se articulam aos elementos da formação integral dos estudantes, na medida em que fomentam a aprendizagem da convivência democrática e cidadã, princípio básico à vida em sociedade (BRASIL, 2017, p. 435).

documento destaca que:

Cabe ao Ensino Religioso tratar os conhecimentos religiosos a partir de pressupostos éticos e científicos, sem privilégio de nenhuma crença ou convicção. Isso implica abordar esses conhecimentos com base nas diversas culturas e tradições religiosas, sem desconsiderar a existência de filosofias seculares de vida (BRASIL, 2017, p. 434). 
Com base nessas orientações, a Secretaria Municipal de Educação de Curitiba declara que organiza o currículo do Ensino Religioso com base na ciência da religião (CURITIBA, 2018) com vistas a atender às aspirações sociais, apoiada no princípio constitucional de laicidade de Estado, no reconhecimento e na valorização da diversidade cultural que se apresenta na escola pública, no pluralismo religioso que compõe a sociedade e na igualdade de tratamento, bem como na atenção às legislações e às políticas públicas que normatizam o sistema de ensino. Importa evidenciar que

Essas Ciências investigam a manifestação dos fenômenos religiosos em diferentes culturas e sociedades enquanto um dos bens simbólicos resultantes da busca humana por respostas aos enigmas do mundo, da vida e da morte. De modo singular, complexo e diverso, esses fenômenos alicerçam distintos sentidos e significados de vida e diversas ideias de divindade(s), em torno dos quais se organizam cosmovisões, linguagens, saberes, crenças, mitologias, narrativas, textos, símbolos, ritos, doutrinas, tradições, movimentos, práticas e princípio éticos e morais (BRASIL, 2017, p. 434).

Nesse horizonte, a Secretaria Municipal de Educação de Curitiba defende em seus documentos orientadores que a escola deve trabalhar sistematicamente através de uma abordagem científica, conceitual e metodológica que respeita a diversidade religiosa e combata qualquer forma de preconceito e intolerância.

Amparada em todas as legislações e diretrizes educacionais brasileiras, a Secretaria Municipal de Educação de Curitiba dispõe de uma organização própria ao que se refere ao componente de Ensino Religioso no contexto do ensino público do município, mantendo uma equipe pedagógica específica para orientar os professores que atuam nesse componente curricular. Na mesma perspectiva, promove ações de capacitação profissional dos professores por meio de formações continuadas e produção de materiais pedagógicos para subsidiar as práticas educativas realizadas nas escolas públicas municipais. 


\section{Desafios para a transversalização curricular da Educação Ambiental no Ensino Religioso: relato dos professores}

Neste tópico apresentam-se e discutem-se os desafios apontados pelas professoras participantes da pesquisa para que a proposta didática de transversalização curricular da Educação Ambiental no Ensino Religioso se efetive nas suas aulas. Esses desafios se configuram na necessidade de criar interconexões que se desenvolvam nas brechas e nos espaços heuristicamente criados pelos professores para superar os hiatos existentes entre a retórica político-institucional e as práticas escolares.

De acordo com as respostas dos participantes P1 (2020) e P2 (2020), um dos impedimentos encontrados para a realização dessa prática refere-se à mecanização do trabalho docente. Esse aspecto impede que o professor compreenda que o papel da Educação escolar é ir além das propostas específicas da sua área de atuação numa tentativa de ruptura com sistemas que fragmentam e burocratizam a prática docente e seus respectivos conteúdos e objetivos. Para ilustrar esse desafio, recorre-se à fala de uma das professoras que participaram da pesquisa:

[...] então, eu não vejo como uma dificuldade, mas talvez um desafio. A gente acaba fazendo um pouco mecânico as coisas, os trabalhos, mudando uma coisa ou outra, mas acaba trabalhando da mesma forma. Então, eu acredito que uma dificuldade seja pensar fora da caixinha mesmo, é estar aberto a essa possibilidade, a começar a ver os conteúdos de uma maneira mais ampla e não só aquele: Ah, o objetivo é esse, então, vou trabalhar isso e isso, trabalhei e acabou". [...] Então, acredito que não é uma dificuldade, mas um desafio de saber utilizar os conteúdos para fazer a assimilação entre o Ensino Religioso e a Educação Ambiental, ainda mais nesses tempos que a gente está vivendo, em que a Educação Ambiental é fundamental. Então, o desafio é superar essa forma de pensamento e levar aos nossos alunos conhecimentos para que eles também consigam pensar fora da caixinha [...] (P1, 2020).

Da mesma forma, a P2 (2020) corrobora que, no conjunto dos desafios para avançar em relação aos processos de transversalização curricular, está a dificuldade que os professores encontram para abordar diferentes saberes, o 
que poderia implicar na ausência de integração entre as áreas do conhecimento e os componentes curriculares.

Os relatos das professoras P1 (2020) e P2 (2020) encontram respaldo em Morin (201 1 , p. 38) que assevera que a Educação está pautada na ciência moderna, cultura científica e técnica disciplinar que "[...] parcela, desune e compartimenta saberes, tornando cada vez mais difícil a sua contextualização". Para esse autor, um dos problemas da Educação são as ciências disciplinares, pois elas formam mentes sem aptidões para contextualizar saberes e integrá-los a diferentes conjuntos. Morin (201 1, p. 39) afirma que "[...] o recorte das disciplinas impossibilita apreender o que está tecido junto".

Sá, Carneiro e Luz (2013, p. 161) advertem que essa racionalização da prática educativa está "[...] frequentemente presente na área de formação de professores e estendem-se mecanicamente à prática escolar". Essa Educação disciplinar, que faz com que o professor ainda exerça uma atuação mecanicista e fragmentada, é fruto de uma inteligência parcelada, compartimentada, mecanicista, disjuntiva e reducionista (MORIN, 2011 ).

Por isso, romper com esse paradigma é desafiador. Porém, esse processo de ruptura, mesmo que limitado por fatores de diferentes naturezas, é imperioso para que os professores possam avançar em suas práticas e incorporar temas que emergem da dinâmica social.

Sobre isso, Viana e Oliveira (2006, p. 4) enfatizam a importância da preparação dos docentes para atender às exigências das demandas sociais, políticas, econômicas e culturais presentes no mundo contemporâneo. Portanto, os autores entendem que "[...] a atuação docente no processo educacional é fundamental para o rompimento de práticas defasadas que ainda se encontram no contexto escolar $[\ldots]^{\prime \prime}$, conforme argumentamos a partir dos depoimentos das professoras que participaram da pesquisa.

Esse desafio também já foi apontado por Torales-Campos (2015) ao enfatizar que o obstáculo se relaciona à dificuldade que as escolas têm em romper com o padrão de currículo disciplinar e hierarquizado que permanece vigente na prática educativa como foi possivel observar a partir dos dados produzidos nesta pesquisa.

Outro aspecto que foi apontado e pode gerar dificuldades para a inserção das temáticas ambientais no componente de Ensino Religioso é a questão do tempo. As participantes P3 (2020) e P6 (2020) compreendem que a 
Desafios para a transversalização curricular da Educação Ambiental no Ensino Religioso

forma como a disciplina e sua carga horária com uma aula por semana estão organizadas dificulta a abordagem de novos temas. Alguns relatos reforçam a importância desta questão.

Tem a questão do tempo. As aulas duram 50 minutos, não tem como ficar desdobrando muitos temas (P3, 2020).

$[\ldots]$

Eu acho que o maior desafio e a maior dificuldade de fazer essa transversalidade é a questão dos conteúdos que não são específicos para o tema, que tem a questão do tempo, né. A gente tem uma aula de 50 minutos [...], você acaba perdendo entre 10 a 15 minutos só para organizar a sala, organizar os alunos. Então, eu acredito que o maior desafio é isso, é no currículo em relação aos conteúdos e a questão do tempo em sala de aula, é muito pouco tempo 50 minutos para você trabalhar os conteúdos e fazer essa transversalidade (P6, 2020).

Embora essas dificuldades possam ser empecilhos para o planejamento e a ação docente, é importante considerar que a transversalidade não propõe um trabalho desarticulado, porque, ao contrário, favorece uma ação 10 mais integrada, na qual o professor pode articular conteúdos e objetivos curriculares e "organizar o trabalho didático-pedagógico integrando eixos temáticos às disciplinas de forma a estarem presentes em todas elas" (BRASIL, 2013). Portanto, a transversalidade refere-se a uma proposta didática que integra a realidade vivida, os problemas sociais relevantes e legitimados como necessários para a formação básica cidadã.

Acredita-se que, à medida que as discussões sobre as possibilidades de realizar a Educação Ambiental na escola se ampliem, o professor se desprenda da leitura limitada sobre os conteúdos na sua prática educativa a partir da transversalidade curricular. Dessa maneira, passará a compreendê-los como pontos de partida para intervir, sem reduzir o interesse das áreas de conhecimento e componentes curriculares, a fim de desenvolver nos estudantes as "[...] capacidades motoras, afetivas, de relação interpessoal e de inserção social [... ]" (ZABALA, 1998, p. 30) para sua formação plena e integral.

Todavia, não se descarta que o tempo de aula pode ser um elemento que pode, de fato, dificultar a prática da transversalização, mas se pontua que é necessário compreender que "[...] todo conteúdo, por mais específico que seja, sempre está associado e, portanto, será aprendido junto com conteúdos 
de outra natureza" (ZABALA, 1998, p. 40). Logo, a transversalidade no contexto curricular pode ser um caminho para tornar o processo de formação escolar ainda mais significativo.

Reforça-se, portanto, a importância de ampliar a compreensão de que as leis e as diretrizes para o desenvolvimento da Educação Ambiental não orientam o professor a separá-la de suas atividades e conteúdos cotidianos, mas indica que os saberes socioambientais precisam encontrar brechas de diálogo com os objetivos das diferentes áreas do conhecimento e construir possibilidades de um atravessamento rizomático na composição dos currículos.

Não obstante, os dados da pesquisa demonstram que, para todas as professoras participantes, o maior desafio está vinculado à falta de conhecimento que possuem sobre a Educação Ambiental e a possibilidade de inseri-la transversalmente na disciplina do Ensino Religioso. Para P1; P2; P3; P4; P5 e P6 (2020) são escassas as oportunidades de formação profissional para que os professores possam compreender e, posteriormente, introduzir as questões socioambientais no componente curricular em questão.

Eu pensei que falta uma formação ampla, né, que aborde os temas transversais com o uso do Ensino Religioso. Se talvez lá, quando eu iniciei nesse percurso com o Ensino Religioso, tivesse tido essa ideia, alguém falado: 'Olha, seria legal trabalhar desta forma'. Talvez, essa prática teria se tornado diferente, o trabalho na prática com os estudantes teria sido focado nisso. Acredito que uma dificuldade é a falta de formação [...] (P1 , 2020).

[...]

Para mim, falta conhecimento docente. Na medida do professor realmente se apropriar do que se exige em cada um dos componentes e conseguir fazer um planejamento com base nesse conhecimento, numa segurança que ele tenha com essas duas áreas. [...] Se ele não conhecer essa possibilidade, se ele não conhecer os documentos que orientam, se ele não conseguir fazer um planejamento que contemple a transversalidade, não vai acontecer. $O$ que eu vejo que acontece comigo agora, com o Ensino Religioso e a Educação Ambiental, é que eu não tenho essa base, eu não tenho essa condição de estar confortável com a Educação Ambiental a ponto de que, nas minhas aulas de Ensino Religioso, possa abordar esses temas que sejam comuns (P2, 2020).<smiles>[CH]1[CH]CC1</smiles> 
Eu tenho conhecimento da disciplina de Ensino Religioso, me falta conhecimento sobre a Educação Ambiental, eu não tenho conhecimento sobre este tema, me falta formação (P3, 2020).

Para a P4 (2020), a Secretaria Municipal de Educação de Curitiba não oferta, de maneira suficiente, cursos que possam contribuir para sua formação profissional na perspectiva da Educação Ambiental. A professora diz que recebe algumas formações continuadas da mantenedora, mas que estas são focadas nas religiões. Segundo ela, "[...] assim fica muito fechado, essa parte de Educação Ambiental fica focada mesmo na área de Ciências" (P4, 2020). Nessa mesma perspectiva, P6 (2020) diz que "[...] para ter essa transversalidade, teria que ter uma conversa, uma adequação, seria preciso a gente sentar, discutir com calma, pesquisar, para que a gente consiga fazer essa integração entre os temas".

As afirmativas das participantes encontram respaldo nos estudos de Viana e Oliveira (2006, p. 10), no qual os autores salientam que para "[...] os docentes ainda é pouco o investimento por parte do sistema educacional em qualificá-los para trabalhar as questões ambientais no ensino formal". Isso

12 poderia provocar um embotamento da ação docente em relação ao necessário esforço interdisciplinar para associar os conteúdos das diversas áreas de conhecimento e componentes curriculares na abordagem de objeto que insurgem da realidade cotidiana.

Para a professora P5 (2020), bem como relatou a P4 (2020), a Educação Ambiental ainda não ganhou espaço no componente de Ensino Religioso. E, ainda, essa realidade também está relacionada à falta de material para estudo e de subsídios para a efetivação de práticas mais inovadoras. Além disso, a professora relata que falta a participação ativa dos diferentes membros que compõem o sistema educativo, expressando que:

Eu acredito que não haja dificuldades para que a gente possa fazer esse tipo de trabalho. O que falta, na verdade, é mais discussão a respeito do assunto, é desenvolver algum tipo de material, de fazer reuniões, formações mais específicas para que a gente possa incluir de uma maneira bem correta no nosso currículo e nos nossos planejamentos (P5, 2020). 
De acordo com o relato da participante, observamos que existe uma teia de relações complexas que precisa ser superada, tendo em vista que as questões apontadas envolvem dimensões teóricas e práticas que reverberam na atuação das professoras. Essa problemática se inicia com a falta de conhecimento científico sobre o tema e se amplia na ausência de discussões que considerem a relevância da integração dos campos de saberes discutidos neste texto. Se não há construção de conhecimento através de material que ofereça subsídios teóricos e práticos, os processos de transversalização perdem sua potência (sentido aristotélico do termo).

Nessa mesma toada, as professoras P4 (2020) e P5 (2020) afirmam que a Secretaria Municipal de Educação de Curitiba não oportuniza discussões para que o componente curricular em tela contemple a transversalidade da Educação Ambiental, o que restringe as possiblidades de debate. Assim, entende-se que se não há momentos de diálogo que possam levar os professores a refletir sobre suas práticas, ou propostas institucionais que estimulem a profusão de iniciativas pedagógicas inovadoras e comprometidas com as necessárias mudanças socioambientais, cria-se uma lacuna entre as demandas sociais e o papel das escolas em relação à formação da cidadania.

No que se refere à formação dos professores, a Resolução $n^{\circ} 2$, de 15 de junho de 2012, que estabelece as Diretrizes Curriculares Nacionais para a Educação Ambiental (DCNEA), aponta que "[...] os professores em atividade devem receber formação complementar em suas áreas de atuação, com propósito de atender de forma pertinente ao cumprimento dos princípios e objetivos da Educação Ambiental" (BRASIL, 2012, p. 3). Por isso, corroboramos a compreensão das participantes de que a transversalidade da Educação Ambiental no Ensino Religioso não vai acontecer se o professor não conhecer essa possibilidade. Conforme Torales-Campos (2015, p. 275), "[...] não há possibilidade de inovação ou transformação curricular sem investimento no desenvolvimento profissional docente".

Viana e Oliveira (2006) reconhecem que a formação dos professores é importante diante da relevância social da inserção das temáticas ambientais nos currículos escolares. Nessa mesma linha, Torales-Campos (2015, p. 270) afirma que "[...] a ação dos professores é imperativa para a efetivação da Educação Ambiental no âmbito escolar". Contudo, se não houver uma formação adequada desses profissionais para desenvolver práticas de Educação Ambiental apoiadas em uma perspectiva crítica, transformadora e 
emancipatória, a escola não cumprirá seu papel de contribuir na luta pela superação das injustiças e desigualdades sociais, muitas vezes associadas a questões ambientais.

Portanto, concordamos com Viana e Oliveira (2006) que o investimento em formação continuada de professores é imprescindivel para que a transversalidade da Educação Ambiental seja efetivada na prática pedagógica realizada dentro da sala de aula por meio dos diferentes componentes curriculares. À medida em que os professores passarem a participar dessas formações, irão adquirir ou ampliar seus conhecimentos sobre esse tema contemporâneo transversal. Desse modo, poderão perceber possibilidades para inserir as temáticas ambientais no seu laborar pedagógico. Nessa tela, recorremos a Carvalho (2019, p. 187) para apontar que as formações continuadas "[...] permitem uma aproximação e uma intimidade maior dos professores com o campo da Educação Ambiental e, consequentemente, maior segurança para pensar, elaborar e executar as práticas ambientais".

No entanto, além da formação docente, as participantes P1 (2020) e P2 (2020) chamam a atenção para outros aspectos que pululam em torno do desafio de inserir a Educação Ambiental nos currículos escolares. Elas asseve14 ram que a inexistência de uma parceria entre professor e pedagogo impacta nas condições de trabalho e é um fator que não favorece a transversalidade da Educação Ambiental no Ensino Religioso.

Para as professoras, o pedagogo ou coordenador pedagógico, associado a outros integrantes da equipe de gestão escolar, deveria estar junto aos docentes para contribuir na elaboração do planejamento das práticas educativas, para ampliar e estimular os estudos a respeito da temática ambiental e para fomentar a reestruturação das estratégias pedagógicas. Essas preocupações estão plasmadas nas seguintes falas das professoras:

Eu acho que é fundamental o papel do pedagogo. É importante destacar o papel do pedagogo nessas amarras dos planejamentos [...]. Eu sinto falta de um pedagogo na escola que seja competente na sua função de fazer a supervisão escolar, contribuindo com o planejamento do profissional [...]. Tem faltado essa formação continuada para o profissional, tem faltado um aporte pedagógico com este pessoal que está lá para fazer este aporte e infelizmente não faz (P2, 2020). 


\section{$[\ldots]$}

Na verdade, a gente sabe que os temas transversais são maravilhosos no papel, nos PCNs. Mas, na prática é diferente do que está escrito no documento. E não tem nenhuma formação assim, em nenhuma das áreas, a gente não escuta falar nisso. Por exemplo, na minha escola, tem a disciplina de Educação Ambiental, mas ela é focada só como disciplina. [...]. A gente está tão acostumada a trabalhar aquela mecanização 'aí, preciso dar conta desses conteúdos' e como os temas transversais são obrigatórios, mas não são cobrados, então, a gente vai passando (P1, 2020).

Considerada a função e a relevância que a Educação exerce na sociedade e que a escola é um espaço privilegiado para a construção dos saberes socioambientais, é preciso chamar a atenção sobre a importância de uma frente pedagógica formada por profissionais capazes de viabilizar o planejamento e a efetivação de intervenções pedagógicas no ambiente escolar.

Compreende-se que, de fato, é necessário reconhecer o papel do pedagogo no favorecimento do diálogo entre os componentes curriculares e os temas transversais contemporâneos. Esse profissional exerce uma tarefa determinante na escola, tanto na organização do trabalho pedagógico, como emerge na fala das participantes, quanto na articulação e na dinamização da prática educativa em favor da Educação Ambiental. Em recente estudo é indicado que o pedagogo deve atuar diretamente junto aos professores, pois é

[...] de suma importância que os coordenadores pedagógicos, ou seja, os profissionais responsáveis pela condução e pelo bom funcionamento do ambiente escolar sejam atuantes e participantes de pesquisa e intervenções no que tange a EA na escola, uma vez que os mesmos fazem parte do processo de ensino-aprendizagem, mesmo não atuando em sala de aula (ALKIMIN; DORNFELD, 2020, p. 2).

Dessa forma, refletir sobre a necessidade de o pedagogo também estar à frente dessas propostas é pertinente, porque isso pode trazer contribuições significativas para que a Educação Ambiental ganhe espaço na prática educativa. A atuação dos pedagogos é um apoio importante para que os professores recrudesçam sua atuação, tanto do ponto de vista teórico como no aprimoramento das estratégias e metodologias de ensino. Essa cooperação pode provocar mudanças no planejamento e na inovação da prática dos 
professores, favorecendo processos de formação e reflexão, tão necessários para a inserção da Educação Ambiental nos currículos escolares.

O processo de transversalização curricular da Educação Ambiental na escola se constitui em um desafio bastante complexo. Ao reconhecer as dificuldades que emergem deste processo, não seria possível deixar de compreender a fala da participante P2 (2020) quando confessa não se sentir apta para planejar e desenvolver sozinha, ações que contemplem as temáticas ambientais no Ensino Religioso. Da mesma forma, Pl diz que, por mais que seja necessária, a inserção da Educação Ambiental não será contemplada no currículo escolar se não houver apoio pedagógico aos professores.

O estudo de Rodrigues (2018, p. 126) também apontou a importância do papel do pedagogo como facilitador da inserção da Educação Ambiental e reconhece que "[...] o pedagogo tem papel fundamental para que as práticas em Educação Ambiental se efetivem [...]". Do mesmo modo, apoiamo-nos em Alkimin e Dornfeld (2020, p. 1) para reforçar a ideia de que "[...] o coordenador pedagógico é peça fundamental para que a EA na escola seja realidade".

Os relatos das participantes evidenciam que a Educação Ambiental é esquecida não somente no cotidiano das práticas escolares, mas também está ausente no contexto maior do sistema de ensino, onde é possível perceber que não há uma preocupação com a relevância da temática nas diferentes áreas de conhecimento e componentes curriculares.

Foi possível observar que, mesmo havendo espaços destinados às discussões e à formação de professores, como é o caso das formações continuadas realizadas pela equipe do currículo de Ensino Religioso, esses momentos formativos não oportunizam aos professores uma reflexão ampla sobre o papel da escola e dos componentes curriculares na resolução dos problemas sociais que emergem de diferentes contextos e afetam a toda a sociedade.

Os argumentos utilizados pelas participantes desta pesquisa revelam que os desafios para transversalizar a Educação Ambiental no Ensino Religioso estão além da formação contínua dos professores, pois também dependem do engajamento de outros sujeitos, sejam colegas professores, pedagogos ou coordenadores pedagógicos, sejam as equipes responsáveis pelo apoio pedagógico na Secretaria Municipal de Educação. Essas preocupações também são evidenciadas no estudo de Viana e Oliveira (2006), em que os autores analisaram a inclusão do tema meio ambiente no currículo escolar. 
Clavdia Loureno Gomes 1 Marila Andiade Tordes Campos

A formação docente é condição básica para a implementação da proposta da Educação Ambiental nos currículos escolares. Entretanto, é necessário que haja um comprometimento maior por parte de todos os responsáveis pelo processo educacional (professores, coordenadores, diretores, secretaria de educação) para que sejam viabilizados meios como a realização de seminários, encontros, debates entre profissionais, com a intenção de que os mesmos compreendam a importância de relacionar os conteúdos das diversas disciplinas com as situações problemas do dia a dia, principalmente no que diz respeito às questões ambientais (VIANA; OLIVEIRA, 2006, p. 131.

Torales-Campos (2015, p. 269) acompanha essa mesma perspectiva ao afirmar que a inserção da Educação Ambiental no sistema educativo, ademais de implicar na formação dos professores, "[...] depende de uma atitude favorável, envolvimento e compromisso não só por parte dos professores, mas também dos gestores e formadores". Portanto, ao tratar do tema a partir do olhar de um grupo de seis professoras, colocamos em evidência que estas estão imersas em uma teia de relações que opera com diferentes dinâmicas, condicionada aos seus contextos e possibilidades, sejam eles materiais sejam simbólicos, mas que constantemente desafiam a práxis das professoras.

Destarte, acreditamos que, à medida que os estudos científicos avançam na direção de melhor elucidar a transversalidade da Educação Ambiental no Ensino Religioso, essa temática tenha mais oportunidade de ser valorizada. É relevante e imprescindível para os sistemas de ensino que as formações de professores caminhem no reconhecimento de que todos os componentes curriculares precisam e devem estabelecer diálogos de modo a unir esforços para garantir os fins e os objetivos da Educação em sua totalidade. Nesse sentido, os professores poderiam encontrar fontes que thes subsidiem, favorecendo, dessa maneira, que ultrapassem a visão utilitarista do componente curricular e dos conteúdos, tão presente na prática educativa.

A superação desses desafios poderá levar os profissionais que atuam na linha de frente das escolas na preparação das crianças, jovens e adultos a compreender e a fazer melhor uso de seus currículos e instrumentos pedagógicos. Aqui se discute o currículo de Ensino Religioso em favor de um processo de ensino e aprendizagem que transcenda os muros das escolas, a partir de uma reflexão transformadora das práticas e dos saberes escolares. Por meio de um olhar mais sensível e comprometido com o desenvolvimento do Ensino Religioso 
Desafios para a transversalização curricular da Educação Ambiental no Ensino Religioso

e da Educação Ambiental, buscou-se oferecer elementos que possam, de fato, ajudar a compreender a realidade vivida para transformá-la (FREIRE, 1996).

\section{Considerações finais}

Este estudo tratou de duas áreas de conhecimentos distintas. Contudo, entre elas, há similaridades de interesses na formação dos sujeitos, nos objetivos, nas práticas escolares e no respeito a qualquer tipo de manifestação da diversidade humana. Do ponto de vista das orientações institucionais, tanto - Ensino Religioso como a Educação Ambiental estão assegurados por leis e diretrizes há décadas (BRASIL, 1996; 2012; 2013; 2017), mas carecem de um maior esforço para que seu desenvolvimento alcance os objetivos pretendidos.

Ao debruçar-nos sobre a proposta da transversalização curricular da Educação Ambiental no componente de Ensino Religioso, revelou-se um conjunto de dificuldades que formam uma teia complexa de desafios que estão associados uns aos outros e que precisam ser debatidos com vista a serem superados.

18 De acordo com os relatos das professoras entrevistadas, um dos principais desafios refere-se à visão fragmentada do saber (MORIN, 2011 1), que implica em barreiras disciplinares que não permitem que os professores organizem inovações curriculares coerentes com as demandas sociais contemporâneas. A ruptura com a perpetuação de intervenções pedagógicas defasadas é inadiável, e a transversalidade é uma proposta didática que busca atender as necessidades que emergem do contexto social e precisam chegar até as escolas.

Outro elemento sinalizado como fator que pode impossibilitar a transversalidade da Educação Ambiental no Ensino Religioso foi a composição do componente e a duração da aula, que se desenvolve uma vez por semana em apenas 50 minutos. No entanto, acredita-se que, à medida que o olhar limitado e pouco reflexivo sobre o papel dos conteúdos curriculares das diferentes disciplinas avance em direção a um trabalho mais integrado e interdisciplinar, a duração das aulas não será um elemento de conflito para que a Educação Ambiental se desenvolva nesse componente curricular, uma vez que se trata de uma dimensão da Educação polissêmica, que, na prática, pode ser conduzida por diferentes concepções e métodos (SAUVÉ, 2005). 
Dessa forma, seria preciso apoiar os professores no aprofundamento de sua compreensão sobre a transversalidade da Educação Ambiental. Isso é vital para que possam compreender que tal abordagem não exige um planejamento e uma prática educativa a mais ou à parte, mas se trata de uma "[...] abordagem curricular integrada e transversal, contínua e permanente em todas as áreas do conhecimento, componentes curriculares e atividades escolares e acadêmicas" (BRASIL, 2012, p. 4).

Nesse horizonte, os conteúdos presentes no currículo tendem a ser percebidos como algo fluído, com porosidade suficiente para se deixar penetrar pelas manifestações sociais da contemporaneidade. Tal horizonte permite desenhar uma realidade possível "[...] a partir de uma relação dialógica, via um planejamento flexível, que possibilite um trabalho escolar problematizador [...]" (SÁ; CARNEIRO; LUZ, 2013, p. 163), coerente com a orientação dada para o desenvolvimento da Educação Ambiental na escola.

Contudo, é necessário um esforço pedagógico no interior das escolas para auxiliar os professores, pois a ausência de aporte foi expressa como um limitador do trabalho desenvolvido pelas participantes. É pertinente chamar a atenção para a atuação dos pedagogos, porque eles atuam como gestores da condução dos processos pedagógicos desenvolvidos na escola, o que inclui os tratamentos das especificidades de todos os componentes curriculares.

Apesar dos encaminhamentos escolares amiúde privilegiarem determinadas áreas do conhecimento e do Ensino Religioso ser tratado como portas dos fundos (FREITAS, 2018), em que pese a transversalidade da Educação Ambiental ser complexa, ambos são considerados essenciais e devem receber igual tratamento e atenção, pois estão institucionalizadas. Portanto precisam ocupar um lugar significativo na escola.

Dessa forma, entende-se que todos os desafios elencados ao longo deste texto estão vinculados a um conjunto multifacetado de fatores, entre os quais a falta de formação profissional em Educação Ambiental. Junte-se a isso, a fragilidade dos conhecimentos que os professores dizem possuir sobre o tema que se constitui em uma problemática a ser enfrentada não só por eles, mas também pelos demais sujeitos responsáveis pela ação pedagógica da escola.

Considera-se que, caso esse processo formativo permanecer inexistente, as intervenções pedagógicas realizadas com os estudantes continuarão 
desarticuladas e distantes das demandas sociais que emergem em diferentes contextos e com ritmos próprios, muitas vezes balizados por elementos culturais. A permanecer essa realidade, os professores continuarão enfrentando os mesmos problemas que dificultam ou impedem inovações em sua práxis profissional.

Se a formação continuada é essencial para a inserção da Educação Ambiental nos currículos escolares (VIANA; OLIVEIRA, 2006), esta não ganhará espaço no âmbito escolar sem investimento na formação dos professores, pedagogos e gestores (TORALES-CAMPOS, 2015). É fulcral que os sistemas de ensino invistam na formação de seus profissionais a fim de que estes, de posse do conhecimento, sintam-se aptos a se tornarem educadores ambientais.

A modo de finalizar esta reflexão, que com certeza seguirá em outros escritos, conclui-se que todos os desafios estão amalgamados e que um remete ao outro. Portanto, a superação desses conflitos implica no envolvimento de todos os profissionais responsáveis pela escolarização dos estudantes e que todos precisam tomar consciência do compromisso social da escola para assumir esta tarefa desafiadora, a partir do seu fazer pedagógico, na busca de alternativas para que a transversalidade da Educação Ambiental se materialize 20 no componente curricular de Ensino Religioso.

\section{Referências}

AGUILAR, Olivia; KRASNY, Marianne. Using the communities of practice framework to examine an after school environmental education program for Hispanic youth. Environmental Education Research, Londres, v. 17, n. 2, p. 217-233, 2011.

ALKIMIN, Gilberto Dias de; DORNFELD, Carolina Buso. A educação ambiental no Ensino Médio do município de llha de Solteira (SP): a visão dos coordenadores pedagógicos. Revista Educação Ambiental em Ação, São Paulo, v. 18, n. 70, p. 1-13, mar./maio 2020.

BRASIL. Lei n 9.394, de 20 de dezembro de 1996. Estabelece as Diretrizes e Bases da educação Nacional. Diário Oficial [da] União, Poder Executivo, Braślia: DF, 23 dez. 1996. Seção 1, p. 27833. 
BRASIL. Resolução $\mathbf{n}^{\circ} \mathbf{2}$, de $\mathbf{1 5}$ de junho de 2012. Estabelece as Diretrizes Curriculares Nacionais para a Educação Ambiental. Brasília, 2012. Disponível em: http://portal.mec. gov.br/dmdocuments/rcp002_12.pdf. Acesso em: 15 mar. 2021.

BRASIL. Diretrizes Curriculares Nacionais para a Educação Básica. Brasília, 2013. Disponivel em: http://portal.mec.gov.br/index.php?option=com_ docman\&view=download\&alias= 13448 -diretrizes-curiculares-nacionais-20 13 -pdf\&ltemid=30192. Acesso em: 9 mar. 2021.

BRASIL. Base Nacional Comum Curricular. Brasília, 2017. Disponível em: http://basenacionalcomum.mec.gov.br/. Acesso em: 10 mar. 2021.

BRASIL. Temas contemporâneos transversais na BNCC: contexto histórico e pressupostos pedagógicos. Brasília, 2019. Disponível em: http://basenacionalcomum.mec.gov.br/ images/implementacao/contextualizacao_temas_contemporaneos.pdf. Acesso em: 9 mar. 2021.

CARVALHO, Andréa Macedônio de. Educação ambiental: análise de uma proposta interinstitucional de formação continuada de professoras da rede Municipal de Ensino de Curitiba/ PR. 2019. 21 ff. Dissertação (Mestrado em Educação) - Programa de Pós-Graduação em Educação, Universidade Federal do Paraná, Curitiba, 2019.

CURITIBA. Secretaria Municipal de Educação. Ensino religioso no Estado laico um desafio para o ensino fundamental: orientações para o trabalho nas escolas públicas municipais de Curitiba: ORGAO, 2018.

FREIRE, Paulo. Pedagogia da autonomia: saberes necessários à prática educativa. São Paulo: Paz e Terra, 1996.

FREITAS, Eliane Maura Littig Milhomem de. Bem-me-quer, malmequer: um estudo sobre a presença do ensino religioso na Base Nacional Comum Curricular. 2018. 237 f. Tese (Doutorado em Ciências da Religião) - Programa de Pós-Graduação em Ciência da Religião, Pontifícia Universidade Católica de São Paulo. São Paulo, 2018.

MEIRA, Pablo Ángel. Outra lectura da historia da educación ambiental e algún apuntamento sobre a crise do presente, AmbientalMente Sustentable, Coruña, v. 4, n. 8, p. 6-43, 2009.

MORIN, Edgar. Os setes saberes necessários a educação do futuro. Tradução Catarina Eleonora F. da Silva e Jeanne Sawaia. 2. ed. rev. São Paulo: Cortez, 2011.

MORIN, Edgar. Ensinar a viver: manifesto para mudar a educação. Tradução Edgard de Assis Carvalho e Mariza Perassi Bosco. Porto Alegre: Sulina, 2015. 
NEVES, Juliana Pereira; TOZONI-REIS, Marília Freitas de Campos. Desafios para a inserção da educação ambiental na escola: em questão a carência formativa do professor a partir de duas pesquisas diagnósticas. In: TOZONI-REIS, Marília Freitas de Campos; MAIA, Jorge Sobral da Silva (org.). Educação Ambiental a várias mãos: educação escolar, currículo e políticas públicas. Araraquara: Junqueira \& Marin, 2014.

PEREIRA SOBRINHO, Osleane Patricia Gonçalves; ZANON, Angela Maria. Dos sentidos à abordagem integradora da educação ambiental no contexto formal do Ensino. Ambiente \& Educação, Rio Grande, v. 21 , n. 1, p. 94-110, 2016. (Dossiê Temático Fundamentos da Educação Ambiental).

PRESTINI, Sirlene Aparecida Matos Martins. Transversalidade e temas transversais na formação inicial do professor de matemática. 2005. 89f. Dissertação (Mestrado em Educação) - Programa de Pós-Graduação em Educação, Universidade Federal do Paraná, Curitiba, 2005.

P1. Entrevista. Curitiba (Paraná), 18 mar. 2020.

P2. Entrevista. Curitiba (Paraná), 21 mar. 2020.

P3. Entrevista. Curitiba (Paraná), 27 mar. 2020.

P4. Entrevista. Curitiba (Paraná), 30 mar. 2020.

22 P5. Entrevista. Curitiba (Paraná), $1^{\circ}$ abr. 2020.

P6. Entrevista. Curitiba (Paraná), 2 abr. 2020.

RODRIGUES, Daniela Gureski. A formação continuada do professor da educação infantil em educação Ambiental. 2018. 158f. Dissertação (Mestrado em Educação) - Programa de Pós-Graduação em Educação, Pontifícia Universidade Católica do Paraná, Curitiba, 2018.

SÁ, Ricardo Antunes; CARNEIRO, Sonia Marchioratto; LUZ, Araci Asinelli. A escola e os sete saberes: reflexões para avanços inovadores no processo educativo. Revista FAEEBA - Educação e Contemporaneidade, Salvador, v. 22, n. 39, p. 159-169, 24, jun. 2013.

SAUVÉ, Lucie. Uma cartografia das correntes em educação ambiental. In: SATO, Michèle; CARVALHO, Isabel Cristina de Moura (org.). Educação Ambiental: pesquisas e desafios. Porto Alegre: Artmed, 2005.

STEVENSON, Robert. Schooling and environmental/sustainability education: from discourses of policy and practice to discourses of professional learning. Environmental Education Research, Londres, v. 13, n. 2, p. 265-285, 2007. 
VIANA, Pedrina Alves Moreira Oliveira; OLIVEIRA, José Everaldo. A inclusão do Tema Meio Ambiente nos currículos escolares. REMEA - Revista Eletrônica do Mestrado em Educação Ambiental, Rio Grande, v. 16, p. 1-17, jan./jul. 2006.

TORALES-CAMPOS, Marília Andrade. A formação de educadores ambientais e o papel dos sistemas de ensino para a construção de sociedades sustentáveis. REMEA - Revista Eletrônica do Mestrado em Educação Ambiental, Rio Grande, v. 32, n. 2, p. 266-282, jul./dez. 2015 (Seção Especial: XV Encontro Paranaense de Educação Ambiental- EPEA).

TREVISOL, Joviles Vitório. A educação em uma sociedade de risco: tarefas e desafios na construção da sustentabilidade. Joaçaba: Edições Unoesc, 2003.

ZABALA, Antoni. A prática educativa: como ensinar. Porto Alegre: Artmed, 1998.

Ms. Claudia Lourenço Gomes

Universidade Federal do Paraná (Brasil)

Programa de Pós-Graduação em Educação: Teoria e Prática de Ensino Grupo de Pesquisa em Educação Ambiental e Cultura da Sustentabilidade Orcid id: https:/ / orcid.org/0000-0003-3590-5996 E-mail: lourencogomesclaudia@gmail.com

Dra. Marília Andrade Torales Campos Universidade Federal do Paraná (Brasil)

Programa de Pós-Graduação em Educação: Teoria e Prática de Ensino Grupo de Pesquisa em Educação Ambiental e Cultura da Sustentabilidade Orcid id: https:/ / orcid.org/0000-0002-4026-6239

E-mail: mariliat.ufpr@gmail.com

Recebido 5 ago. 2021

Aceito 28 set. 2021 